\title{
The Expression of Corazonin Neurons in Larvae Stage of Scuttle Fly
}

\author{
Hohyun Park ${ }^{\dagger, *}$ \\ Department of Biomedical Laboratory Science, Mokpo Science University, \\ Mokpo-si, Jeollanam-do 58644, Korea
}

Scuttle fly which moves abruptly after standing for a while and stop suddenly to rush off again, is a fly species in the Phoridae family. This species like rotten organic materials and it is known to proliferate even in the industrial materials including organic solvents. These characteristic behaviors of the scuttle fly seem to be related to muscular and nervous system or neurotransmitters. Thus, we focused at the neurotransmitter, corazonin (Crz) that is known to be related to resistance to stress and investigated the developmental process of the neurons in the scuttle fly. Corazonin is a neuropeptide being expressed in the central nervous system (CNS) and is known to control mainly physiological functions and behaviors. Its many functions that have been proposed are still in controversy. In this studies, we found that there are three groups of corazoninergic neurons in the larval CNS of the scuttle fly and these neurons undergo distinguishable changes through metamorphic process compared to different fly species. Larva has 3 pairs of Crz neurons at the dorsolateral area of the brain, 1 pair at the dorsomedial brain and 8 pairs at the ventral nerve cord.

Key Words: Corazonin, Scuttle fly, Lavae stage, Central nervous system

\section{서 론}

곤충의 신경 펩티드는 다양하고 다기능 신호 물질로서 (Hökfelt, 1991; Nässel, 2002; Taghert and Veenstra, 2003; Baraban and Tallent, 2004; Hauser et al., 2006; Hummon et al., 2006), 일반적으로는 중추신경계에서 분리된 상동 집단의 신경세포에서 발현된다고 하였고, 이 집단은 다른 신경 펩티드에 비해 크기가 다르다고 보고되었다(O'Shea and Schaffer, 1985; Benveniste et al., 1998; Nässel, 2002; Allan et al., 2003; Allan et al., 2005; Gauthier and Hewes, 2006; Santos et al., 2007). 따라서, 이러한 우화 호르몬과 같은 일부 초 파리 신경 펩티드는 균일한 신경세포에서 매우 작은 숫 자로 발견된다고 보고되고 있었다(Horodyski et al., 1993;
McNabb et al., 1997; Verleyen et al., 2004; Terhzaz et al., 2007). Corazonin은 신경 팹티드로서 곤충 등에서 다양한 생리 학적 기능 또는 행동을 조절하는 중요한 역할을 수행한 다고 알려져 있다. 이것은 일반적으로 체액(hemolymph)이 방출되는 측심체(corpora cardiaca)의 축삭(axon)을 가지고 있는 전대뇌(protocelebrum)의 외측부(pars lateralis)에서 큰 신경내분비세포에 의해 생산된다고 한다(Altstein and Nassel, 2010; Nässel and Winther, 2010). Corazonin 팹티드는 서열 및 구조가 매우 다른 곤충 종 사이에 보존되어 있고, 종 특이하게 다양한 생리적 기능에 영향을 미치는 것으로 밝혀져 있었다(Sha et al., 2012).

Corazonin은 아미노산 서열 carboxyl - Glu - Thr - Phe Gln - Tyr - Ser - Arg - Gly - Trp - Thr - Asn - amine으로 11개의 펩티드(undecapepide) 구조로 되어 있으며, 이 펩티드의 말

Received: August 26, 2020 / Revised: September 9, 2020 / Accepted: September 10, 2020

*Professor.

${ }^{\dagger}$ Corresponding author: Ho Hyun Park. Department of Biomedical Laboratory Science, Mokpo Science University, 413-1 Yeongsan-Ro, Mokpo-si, Jeollanam-do 58644, Korea.

Tel: +82-61-270-2745, Fax:+82-61-270-2745, e-mail: phh7082@hanmail.net

(C) The Korean Society for Biomedical Laboratory Sciences. All rights reserved.

(c) This is an Open Access article distributed under the terms of the Creative Commons Attribution Non-Commercial License (http://creativecommons.org/licenses/by-nc/3.0/) which permits unrestricted non-commercial use, distribution, and reproduction in any medium, provided the original work is properly cited. 
단은 아미드화 되고 $\mathrm{N}$-말단 측에서 $\mathrm{pGlu}$ 에 의해 차단되 어 있다고 보고되었다(Veenstra, 1989).

지금까지 corazonin의 신경조절 및 생리적 기능과 관 련하여 곤충(insects)과 일부 척추동물(vertebrates)에서 많 은 연구가 있었다. 곤충에서는 처음으로 미국 바퀴벌레 인 Periplaneta americana의 측심체(copora cardiaca)에서 corazonin이 추출되어 심장박동을 강력하게 조절하는 펩 티드라고 연구 발표가 된 후 많은 기능들이 보고되었다 (Veenstra, 1989; Tawfik et al., 1999; Tanaka, 2001; Yerushalmi et al., 2002).

Corazonin의 기능에 대해서는 특히 초파리에서 많은 연 구가 이루어졌다. 초파리에서 corazonin 생산 뉴런이 도파 민 생산(Zhao et al., 2010)과 생리학적 또는 영양학적 스트 레스로 유도된 행동에 대한 반응, 트레할로오스(trehalose) 레벨의 조절(Lee et al., 2008), 교미기간과 정자운반(Tayler et al., 2012)과 관련성이 있다는 것이 보고되었다. Corazonin 뉴런과 상호작용하는 신경전달물질로 도파민(dopamine)이 라고 하였으며, 스트레스를 받는 동안 변형된 도파민 합 성과 표현형이 도파민의 신호의 유전적 차이와 관련이 있다고 보고하였다(Rauschenbach et al., 1993; Gruntenko et al., 2004; Menzies et al., 2005; Neckameyer and Weinstein, 2005). 또한 corazonin 뉴런의 방출은 소화관의 영양분 양 또는 질을 나타내는 신호에 의해 조절된다고 제안되었다 (Veenstra, 2009). 기아상태 및 기타 생리적 스트레스로 인 한 많은 행동 반응들 중에서 궁극적으로 에너지 보유량 의 추가 손실이 발생하거나 해로운 스트레스 효과가 악 화됐을 때 corazonin 뉴런의 활성 수준이 높게 나타난다는 보고도 있었다(Isabel et al., 2005; Lee and Park, 2005).

또한 corazonin은 인간과 같은 척추동물의 뇌하수체에 서 분비되는 황체형성호르몬(luteinizing hormone, LH)과 난 포자극호르몬(follicle stimulating hormone, FSH)의 방출을 자극하는 성선자극호르몬(gonadotropin releasing hormone, $\mathrm{GnRH})$ 과 유사한 기능을 하는 물질이라고 보고가 되어 있 었다(Cazzamali et al., 2002; Park et al., 2002).

Scuttle fly와 공통적인 구조와 특징을 많이 가지고 있 고 최근에 연구가 많이 이루어지고 있는 초파리 종인 $D$. melanogaster에서도 corazonin 뉴런이 말기 배에서 애벌레 3 령 시기까지 24 개 세포로 구성되어 있는 3 개의 신경그룹 에서 나타났다고 보고되었고(Shiga et al., 2003; Park, 2018), corazonin 뉴런이 복신경색(ventral nerve cord, VNC)에서 하 나의 신경그룹, 대뇌(brain)에서 두 개의 신경그룹을 포함 하고 있다고 하였다(Choi et al., 2005; Lee et al., 2008; Choi,
2009; Park et al., 2018). 대뇌에서 등측 내 corazonin 뉴런은 유충호르몬(juvenile hormone)과 지질동원호르몬(adipokinetic hormone)을 생산하는 후두 복합체에서 발현되고, 성충 시 기까지 등측면 하나의 신경그룹에서 지속적으로 발현된다 고 하였다. 또한 Corazonin은 복부 신경절 뉴런에서 개재 뉴런 네 개의 새로운 종류의 그룹과, 시엽 외측부의 하나 의 엽 당 6 8개의 많은 신경세포에서 집단으로 발현된다 고 보고되었다(Choi et al., 2005; Choi et al., 2006; Lee et al., 2008; Lee et al., 2011).

이렇게 corazonin이 생산되는 뉴런의 공간적인 분포구 역은 비교적 중추신경계 안에 잘 보존되어 있고(Veenstra and Davis, 1993; Cantera et al., 1994; Hansen et al., 2001; Choi et al., 2005; Roller et al., 2003; Roller et al., 2006; Verleyen et al., 2006), 신경세포와 신경분비세포의 작은 집합체로 발현 된다고 하였다(Choi et al., 2005; Choi et al., 2008). 뇌의 주 요한 발현 부위는 외측부분(pars lateralis)에 존재하는 신경 그룹이고, 이 부위 이외에도 종(species)에 따라서 종 특이 적 발현 부위가 발견되고 있다. 특히 시엽 수질(optic lobe medulla)에서 corazonin mRNA 발현을 하는 수많은 뉴런은 오직 Drosophila melanogaster에서만 많이 관찰된다고 보고 되었다(Choi et al., 2005; Lee et al., 2008).

애벌레가 번데기를 거쳐 성체로 발생하는 동안 corazonin 뉴런은 세포자연사(apoptosis)에 의해 그 숫자와 분 화가 크게 변하게 되고, Drosophila에서 면역 반응된 약간 의 corazonon 뉴런은 세포자연사 결과로 변태하는 동안 사라진다고 보고되었다(Lee et al., 2008). D. melanogaster의 애벌레 시기에서 복신경색(ventral nerve cord, $\mathrm{VNC}$ )에 집합 된 corazonin 뉴런은 초기 번데기 시기의 중추신경계(CNS) 가 발생하는 동안에 제거되고, 후기 번데기 시기가 발생 하는 동안 전대뇌(protocerebrum)의 등중앙(dorsomedial)에 서 corazonin 뉴런의 한 쌍이 제거된다고 하였다(Choi et al., 2005; Choi et al., 2006; Choi, 2009; Lee et al., 2008; Lee et al., 2011). 또한 복신경색의 corazonin 뉴런은 전구세포로부터 원래 분화되었고, 만약 발생하고 있는 배아에서 세포자연 사를 거치면서도 전구세포가 생존한다면 corazonin을 생 산하는 뉴런으로 분화될 수도 있다고 하였다(Novotny et al., 2002; Lundell et al., 2003; Karcavich and Doe, 2005). 대부 분의 곤충에서 신경세포의 세포자연사는 주로 두 개의 뚜 렷한 발생 시기에 발생되는데 첫 번째가 변태하는 동안, 두 번째가 성충 발생 직후 일어난다고 보고되었다(Kimura and Truman, 1990; Truman, 1990; Robinow et al., 1993; Awad and Truman, 1997; Draizen et al., 1999; Brodsky et al., 2000; 
Table 1. Base sequences of primers used for PCR amplification in scuttle fly of corazonin gene

\begin{tabular}{cc}
\hline \hline Name of primers & Sequences $\left(5^{\prime} \rightarrow 3^{\prime}\right)$ \\
\hline Scut $5^{\prime} \mathrm{Cr} z$ HindIII & $5^{\prime}$ - cgaagcttGAGTCGTATTCCGATATTC \\
Scut3 $3^{\prime} \mathrm{Crz}$ XbaI & $5^{\prime}$ - ggtctagaCTTCAAATGCGAAACCACA \\
\hline
\end{tabular}

Choi et al., 2006; Tan et al., 2011; Winbush and Weeks, 2011).

지금까지 진행된 corazonin 뉴런에 대한 연구들을 종합 해 보면 초파리를 비롯한 많은 곤충에서 corazonin 뉴런 발현과 기능에 대해 증명되고 있는 것을 볼 수가 있었다. 그래서 본 연구에서는 아직까지 corazonin에 대한 연구가 되어 있지 않은 scuttle fly를 대상으로 먼저 애벌레 시기의 중추신경계에서의 발현되는 corazonin 뉴런에 대해 연구해 보고자 한다.

\section{재료 및 방법}

\section{사육}

실험에 이용한 scuttle fly는 Megaselia scalaris라는 학명을 가진 fly이며, 초파리와 동일한 먹이를 이용하여 사용하였 다. 사육을 위하여 증류수 $250 \mathrm{~mL}$ 에 dextrose $16 \mathrm{~g}$, yeast flakes $6.5 \mathrm{~g}$, cornmeal $20 \mathrm{~g}$, agar $2.25 \mathrm{~g}$ 을 교반기를 이용하여 혼합하고 전자렌지에서 10 분 정도 끓어 넘치지 않을 정 도로 가열하였다. 그리고 methylparaben $6.25 \mathrm{~mL}$ 를 천천히 떨어뜨려서 혼합하고 배지 통에 부은 후 식힌 다음 성충 을 이동시켜 사육을 하였다. 사육은 1 주일 간격으로 다른 배지에 성충을 옮겨서 지속적으로 시행하였다. 제작된 사 육 배지는 $4^{\circ} \mathrm{C}$ 냉장고에 보관하였으며 사용 전 실온에 맞 추기 위해 미리 꺼내 놓은 후 사용하였다.

\section{중추신경계 채취}

Scuttle fly을 애벌레(larvae) 시기 2령 2 3일, 3령 3 5일 과 번데기(pupae) 시기 1 3일, 4 6일, 7 9일, 10 12일, $13 \sim 15$ 일 그리고 성충(adult) 시기별로 각각 5 개 이상의 개체를 사용하였다. $0.1 \%$ tween 20 이 포함되어 있는 PBS (phosphate buffer solution, $\mathrm{pH}$ 7.0)가 채워져 있는 홈이 파인 슬라이드에 개체를 담근 상태로 실체현미경(stereomicroscopy) 상에서 가늘고 정밀한 핀셋을 이용하여 애벌레, 번 데기, 성충의 껍질부분을 찢어가면서 채취하였고, 중추신 경계 조직인 대뇌와 복신경색 조직을 적출하여 그 형태 를 관찰하였다. 발생 단계별로 채취된 중추신경계 조직을 $4 \%$ paraformaldehyde 용액에 넣은 후 $4{ }^{\circ} \mathrm{C}$ 냉장고에 1 시간
이상 고정하여 보관하였다.

\section{Probe 제작}

제자리혼성화법(ISH)으로 corazonin을 검출하기 위해 RNA probe를 제작하였다. 먼저 scuttle fly의 DNA를 phenol /chloroform 법으로 추출하였다. Primer는 corazonin gene의 특이한 염기서열을 선택하고 primer의 앞부분에는 subcloning에 필요한 제한효소 부위를 추가하여 주문 제작하 여 PCR을 시행하였다(Table 1). PCR의 조성은 $10 \mathrm{X}$ PCR buffer $2 \mu \mathrm{L}, 10 \mathrm{mM}$ Scutt 5' Crz HindIII primer $1 \mu \mathrm{L}, 10 \mathrm{mM}$ Scutt 3' Crz XbaI primer $1 \mu \mathrm{L}$ (Kim et al., 2013, Genbank KF318884.1), 2.5 mM dNTP 1.6 $\mu \mathrm{L}$, DNA Taq polymerase 1 unit (Elpis, Korea), template DNA 1 10 ng, 그리고 증류수를 추가하여 최종 부피 $20 \mu \mathrm{L}$ 가 되도록 하였다(Fig. 1). PCR 은 전변성(pre-denature) $94^{\circ} \mathrm{C} 2$ 분, 변성(denature) $94^{\circ} \mathrm{C} 1$ 분, 결합(annealing) $56^{\circ} \mathrm{C} 1$ 분, 신장(extension) $72^{\circ} \mathrm{C} 1$ 분 과정을 30 회 반복 수행하고 후신장(post-extension)은 $72^{\circ} \mathrm{C}$ 에서 5 분 간 진행하였다. $\mathrm{PCR}$ 증폭 산물은 $\mathrm{EtBr}$ (ethidium bromide)로 염색한 후 $1.6 \%$ agarose gel에서 전기영동(RunOne Electrophoresis Cell, Embi Tec, USA) 하여 UV transilluminator 상에 서 밴드를 확인하였다.

증폭 PCR 산물을 pGEM-T Easy vector (Promega Corporation, Madison, WI, USA)에 삽입하여 T7 프로모터를 연결 하였다. 이 백터를 주형으로 in vitro transcription을 시행하 여 RNA 탐침을 만들었다. Digoxygenin으로 표지된 탐침을 만들기 위해 10X T7 RNA polymerase buffer $2 \mu \mathrm{L}, 50 \mathrm{mM}$ DTT $2 \mu \mathrm{L}, 20 \mathrm{mM}$ 의 NTP mixture $1 \mu \mathrm{L}, 10 \mathrm{mM}$ Dig-11-UTP $1 \mu \mathrm{L}$, RNase inhibitor 20 unit, template DNA $20 \sim 1 \mu \mathrm{g}$, T7 RNA polymerase 50 unit, 그리고 RNase free 증류수를 넣어 최종 부피 $20 \mu \mathrm{L}$ 를 만들어 $42^{\circ} \mathrm{C}$ 에서 2 시간 반응하고 $1.6 \%$ agarose gel에 전기영동 하여 Dig labeling의 여부를 확인하 였다.

제작된 corazonin RNA Dig-probe의 조직 침투 효율성을 높이기 위해서 fragmentation 과정을 실시하였다. 먼저 Diglabeling 된 in vitro transcription 산물에 $2 \mu \mathrm{L}$ 의 DNase I을 넣고 $37^{\circ} \mathrm{C}$ 에서 15 분간 incubation 하여 주형 $\mathrm{DNA}$ 를 절단 
A

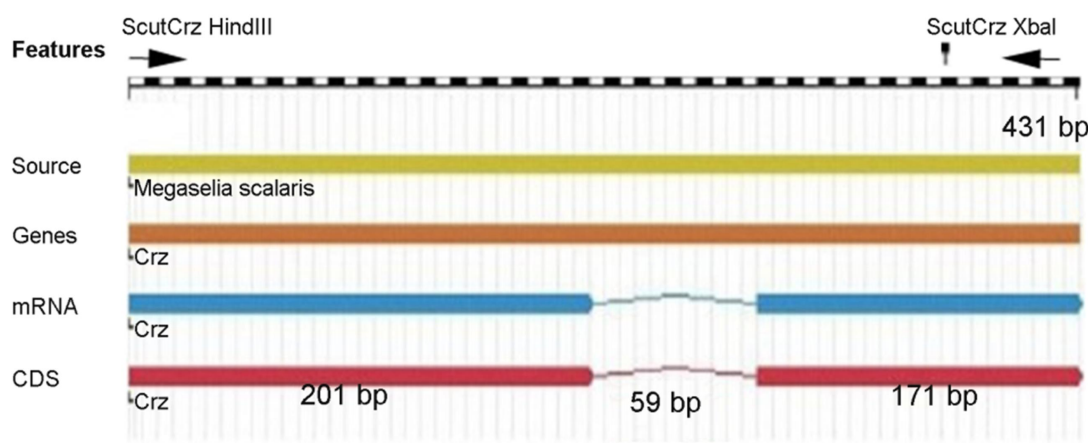

B

$>$ Genomic DNA (431 bp; intron 59) sequences

Scut5' Crz

gagtcgtattccgatattcaatagcaaaATGATAAGAATGTTTGTGGTTCCTTTGTTATTCTTGGGTCTATGTTTGAGCTGTATGGGCCA AACGTTCCAATATTCTCGAGGATGGACAAATGGAAAACGAGCCTCATCTGATATGGACGTTCTTAATCCATTCAATGTTGGA GATTCTGTAATTGAAAATAAACTAGAGAGgtaagtgacatttaaaggaccaattataatttatagatataatttgcttccaatttagATGTTTAAT GCTCCTACAAAGATGTTCCCATTTATCTCTAAAGGTGGAGTGAATAAGAAATTCTATAAAAATGGCAGTCCCGAAATGTTTG ATGAGCTTTtttgattaaaatatttaaaatgtttcgttttgtggtttcgcatttgaag Scut3' $\mathrm{Crz}$
Fig. 1. Structure of $\mathrm{Crz}$ gene in scuttle fly. (A) map for the Crz coding region, (B) sequences of the genomic $\mathrm{Crz}$ gene. The coding sequences are shown in capital letters and 5'-UT, intron, 3'-UT sequences are shown in lower case.
하고 DNase I의 활성을 멈추기 위하여 $0.2 \mathrm{M}$ EDTA (RNase free) $2 \mu \mathrm{L}$ 를 넣었다.

그 다음으로 nucleotide 조각을 제거하고 RNA의 농축 을 위해서 0.1 volume의 $5 \mathrm{M} \mathrm{LiCl}$ 와 2.5 volume의 $100 \%$ Ethanol을 넣고 $-70^{\circ} \mathrm{C}$ 에서 30 분간 침전 후 $4^{\circ} \mathrm{C}$ 에서 15 분 간 $12,000 \mathrm{xg}$ 로 원심분리 하고 $70 \%$ ethanol를 이용하여 수 세를 실시하였다. 침전된 RNA는 5 분 동안 공기 중 상태 에서 말린 후 hydrolysis buffer $(40 \mathrm{mM} \mathrm{NaHCO} / 60 \mathrm{mM}$ $\mathrm{Na}_{2} \mathrm{CO}_{3}, \mathrm{pH} 9.2 \sim 10.2$ )에 넣고 $60^{\circ} \mathrm{C}$ 에서 10 분간 fragmentation을 실시하였다. 마지막으로 $10 \mu \mathrm{L}$ 의 $1 \mathrm{M}$ Tris $(\mathrm{pH}$ 7.5), $300 \mu \mathrm{L}$ 의 in situ hybrix buffer, 그리고 $1 \mu \mathrm{L}$ 의 RNase inhibitor를 넣고 $-20^{\circ} \mathrm{C}$ 보관하여 사용하였다.

\section{제자리혼성화(ISH) 방법}

4\% paraformaldehyde 용액에 고정된 중추신경계 조직을 먼저 PBTw $(0.1 \%$ tween 20 in phosphate buffer solution, $\mathrm{pH}$ 7.0)로 충분히 수세하여 고정액을 완전히 제거하였다. 고 정액이 제거된 다음 평형 형성(equilibration)을 시키기 위 해 실온에서 PBTw:hybrix $(1: 1)$ 로 반응시킨 다음 $60^{\circ} \mathrm{C}$ 에서 $3 \sim 4$ 시간 정도 hybrix 용액 $(50 \%$ deionised formamide $50 \mathrm{~mL}$, 5X SSC $25 \mathrm{~mL}, 100 \mu \mathrm{g} / \mathrm{mL}$ tRNA $0.5 \mathrm{~mL}, 100 \mu \mathrm{g} / \mathrm{mL}$ ssDNA $1 \mathrm{~mL}, 50 \mu \mathrm{g} / \mathrm{mL}$ Heparin $45 \mu \mathrm{L}, 0.1 \%$ Tween-20, $1 \mathrm{~mL}, \mathrm{dH}_{2} \mathrm{O}$ $22.5 \mathrm{~mL}$ )에 전혼성화(prehybridization) 시켰다.
전혼성화가 끝나기 전에 미리 탐침(probe)을 $100^{\circ} \mathrm{C}$ 에서 10 분 정도 변성(denature)시킨 후 바로 얼음물에 3 분 이상 담가서 다시 회복되지 못하게 하고 $60^{\circ} \mathrm{C}$ 에 반응시킨 전 혼성화 용기에 탐침(probe)를 혼합하여 12 14시간 정도 반응시켜 혼성화(hybridization) 시켰다. 혼성화가 끝나면 hybrix와 PBTw의 비율을 tube에 5:0, 4:1, 3:2, 2:3, 1:4, 0:5로 미리 만들어 $60^{\circ} \mathrm{C}$ 로 담가둔 후 단계별로 10 분 동안 $60^{\circ} \mathrm{C}$ 온도상태에서 반응을 시킨 후, 실온에서 $\mathrm{PBTw}$ 로 깨끗이 다시 한번 수세를 하였다. 비특이적인 반응을 차단하기 위하여 정상 동물 혈청인 BSA (bovine serum albumin)와 NSS (normal sheep serum)를 PBTw에 일정량을 희석하여 2시간 동안 blocking 단계를 시행하였고, 반응이 끝난 후 blocking 시약을 제거한 후 PBTw에 항체(anti-digoxigenin$\mathrm{AP}$ Fab fragments, Roche Diagnostic, Germany)를 1:000으로 희석하여 2 시간 동안 반응시켰다.

항체 반응이 끝난 후 $\mathrm{PBTw}$ 에 여러 번 수세하고 검출 완충액(detection buffer, $\mathrm{pH}$ 9.5)를 반응시킨 후 alkaline phosphate (AP) 기질(substrate)인 NBT/BCIP 저장 용액(Roche Diagnostics, Germany)과 검출 완충액을 $1: 100$ 희석하여 20 분 간격으로 발색되는 것을 실체현미경으로 관찰하였 고, 발색이 완료되었을 때 $\mathrm{PBTw}$ 으로 반응을 정지시키고 철저하게 수세를 하였다.

제자리혼성화법이 완료된 중추신경계의 조직은 glycerin 
을 $\mathrm{PBTw}$ 에 각각 $50 \%, 70 \%$ 농도 단계를 거쳐서 중추신 경계 조직을 올바른 방향으로 슬라이드에 위치시킨 후 cover glass로 봉입한 후 광학현미경(light microscopy, LEICA $\mathrm{ICC} 50 \mathrm{HD}, \mathrm{Germany)}$ 상에서 관찰하여 사진을 촬영하였다.

\section{결 과}

Scuttle fly의 2령 애벌레의 중추신경계 조직에서 corazonin 생산 뉴런은 크게 세 개의 그룹으로 나타났다. 뇌 조직에서는 전대뇌(procerebrum) 양쪽 시엽(optic lobe, OL) 이 만들어지는 등측면(dorsolateral, DL) 가장자리에서 세 쌍의 corazonin 발현 뉴런들이 진하게 관찰이 되었다. 또 한 양쪽 대뇌 조직의 중앙 맨 앞쪽에 인접한 부분인 등 중앙(dorsomedial, DM) 부위에 한 쌍의 corazonin 뉴런이 뚜렷이 발현되었다. 복신경색 조직에서는 좌우 대칭으로 총 여덟 쌍의 corazonin 뉴런이 뚜렷하게 관찰되었다(Fig.
2A). 대뇌 조직을 확대 해보면 보는 각도나 초점 깊이에 따라 두 개의 corazonin 뉴런이 겹쳐 보이거나 하나만 관 찰되기도 하였다(Fig. 2B). 그러나 적당한 각도와 깊이에 서는 세 쌍의 뉴런이 corazonin을 뚜렷이 발현하고 있었 고, 앞쪽 중앙에서 약간 빗겨난 좌측과 우측에 두 개의 corazonin 뉴런이 관찰되고 있었다(Fig. 2C). 복신경색에서 관찰된 여덟 쌍의 corazonin 생산 뉴런은 좌우 가장자리 에서 정확히 좌우대칭으로 발달하였다. 여덟 쌍의 뉴런들 중 앞 두 쌍의 뉴런에서 corazonin 발현이 가장 강하게 나 타났다. 측면에서 보았을 때 이 두 쌍의 뉴런은 다른 뉴 런 쌍들 보다 더욱더 등 쪽에 가까이 위치하여 다른 뉴 런 쌍들과 초점거리를 동시에 맞추기가 어려웠다. 세 번 째 뉴런 쌍 이후의 corazonin 뉴런 쌍들은 거의 동일한 평 면 상에 위치하여 좌우대칭으로 배열되어 있었고 가장 마지막 쌍의 크기와 발현 강도가 가장 낮았다(Fig. 2D).

3 령 애벌레 시기의 중추신경계 조직에서도 corazonin
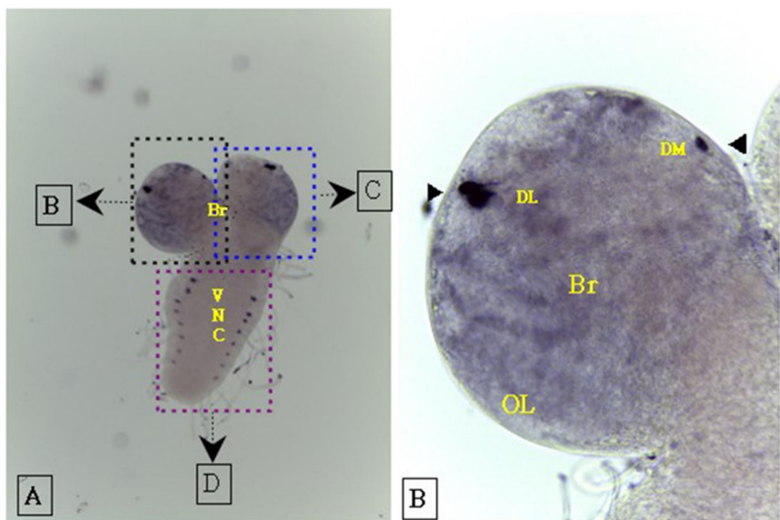

\section{A}

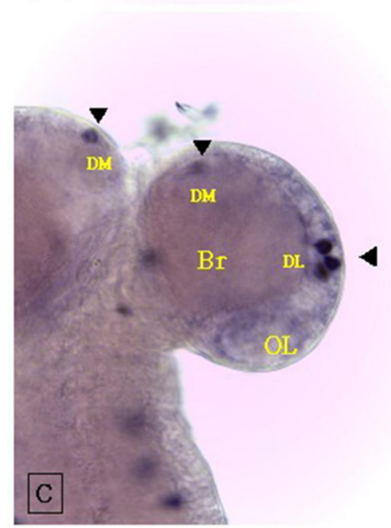

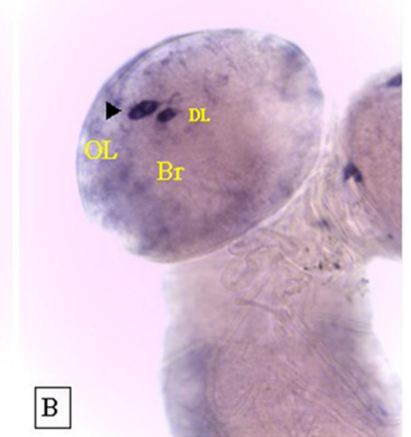

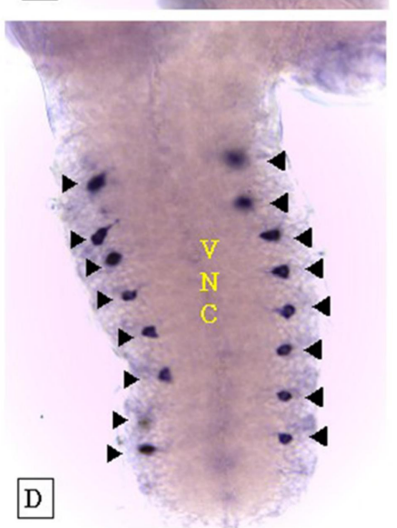

Fig. 2. Identification of corazoninergic neurons in CNS of scuttle fly larva at 2-nd instar stage by in situ hybridization. (A) whole sample $(\times 100),(\mathrm{B}, \mathrm{C}, \mathrm{D})$ partial enlargement of CNS $(\times 400)$. Br; brain, DL; dorsolateral, DM; dorsomedial, VNC; ventral nerve cord, OL; optic lobe.

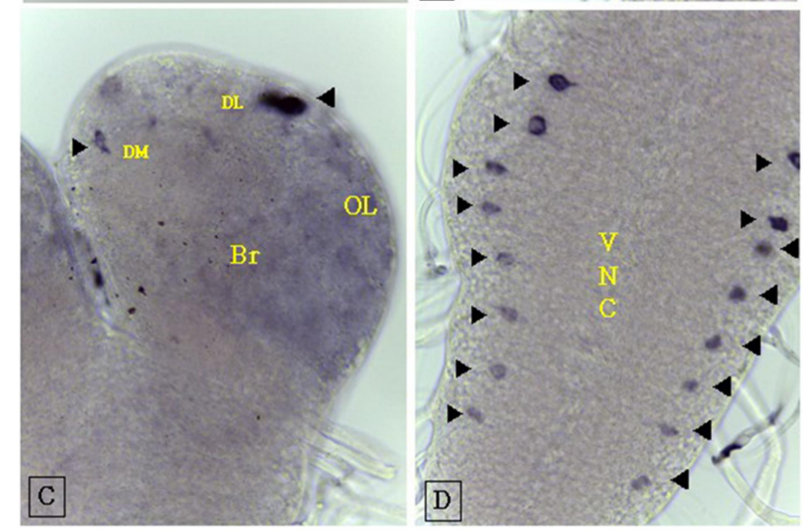

Fig. 3. Identification of corazoninergic neurons in CNS of scuttle fly larva at 3-rd instar stage by in situ hybridization. (A) whole sample $(\times 100),(\mathrm{B}, \mathrm{C}, \mathrm{D})$ partial enlargement of CNS $(\times 400)$. Br; brain, DL; dorsolateral, DM; dorsomedial, VNC; ventral nerve cord, OL; optic lobe. 
뉴런의 발현은 애벌레 2령 시기와 비슷한 패턴을 보였다 (Fig. 3A). 다만 전대뇌의 등측면(DL) 부분에 corazonin 뉴 런 보다 전대뇌 등중앙(DM) 부분에서 한 쌍의 뉴런의 발 현이 약해지고 3 령 후기의 애벌레에서는 이 뉴런 쌍이 관찰되지 않을 때도 있었다(Fig. $3 \mathrm{~B}, \mathrm{C}$ ). 복신경색 조직도 마찬가지로 좌우 대칭으로 여덟 쌍의 corazonin 중 앞 쪽 두 쌍의 corazonin 뉴런은 뚜렷이 corazonin을 발현하고 있 었지만 세 번째 뉴런 쌍 부터는 위쪽에서 아래 쪽으로 갈 수록 corazonin 발현 정도가 점점 약해지는 특징을 볼 수 가 있었다(Fig. 3D).

\section{고 찰}

신경계의 구조와 아울러 동물의 행동에 큰 영향을 미 치는 요인은 신경전달물질이다. 여러 가지 신경전달물 질들 중에서 우리는 다양한 수준, 다양한 조직에서 곤충 행동에 영향을 미치는 corazonin에 주목하였다. Corazonin 은 각종 스트레스 상황에 대응하여 군집의 행동을 조절 (Tawfik et al., 1999)하고 피부색소에 영향(Veenstra, 1991; Tawfik et al., 1999; Tanaka, 2001; Tanaka et al., 2002a; Porras et al., 2003)을 미치며 생식 활동(Tayler et al., 2012), 섭식 활동(Veenstra, 2009), 심장박동(Veenstra, 1989; Tawfik et al., 1999; Tanaka, 2001; Yerushalmi et al., 2002) 등을 조절하는 것으로 알려져 있기 때문이다.

우리는 이미 밝혀진 scuttle fly corazonin 유전자(Fig. 1) 의 암호화 부위를 분석하여 아미노산 서열을 확인하였다. 위 그림(Fig. 4)에서 보이듯이 scuttle fly의 corazonin의 활성 undecapeptide는 알려진 corazonin 11-peptide와 달리 carboxyl - Gln - Thr - Phe - Gln - Tyr - Ser - Arg - Gly - Trp - Thr Asn - amine으로 첫 번째 아미노산이 E (glutamic acid, glu) 에서 Q (glutamine, gln)로 변이가 되어 있었다. 이 사실은 scuttle fly에서 corazonin이 다른 곤충에서 보이는 기능들과 다른 변이된 기능을 가질 수 있음을 시사한다.

Corazonin의 기능 변이를 추론할 수 있는 또 다른 데이 터는 corazonin 발현 뉴런의 발달 과정 상의 차이에서 찾 을 수 있다. 다른 곤충들과 마찬가지로 scuttle fly는 생활사 에서 애벌레, 번데기, 성체의 변태 과정을 거치는데 이런 변태 과정에서 중추신경계의 구조 뿐만 아니라 특정 뉴런 의 생성과 사멸이 다양하게 나타날 것이다. Corazonin 발현 뉴런은 제자리혼성화법(ISH)을 이용해 corazonin mRNA의 발현 여부를 확인하는 방법으로 검출하였다(Fig. 2-4).

초파리 종인 Drosophila melanogaster에서는 말기 배에서
애벌레 3 령시기까지 24 개 세포로 구성되어 있는 3 개의 신 경그룹에서 corazonin 뉴런이 발현된다고 보고가 되었다 (Shiga et al., 2003, Park, 2018). Scuttle fly에서도 마찬가지로 애벌레 2,3 령 시기의 중추신경계 조직을 채집하여 제자리 혼성화법(ISH)을 시행하여 corazonin 유전자의 발현 유무 를 관찰한 결과, 애벌레 2,3 령 시기에서의 중추신경계 대 뇌 조직에서 등중앙( $\mathrm{DM})$ 한 쌍, 등측면(DL) 세 쌍, 복부 신경색 조직에서 여덟 쌍의 동일한 세 개의 신경그룹에 서 24개의 세포가 발현되고 있는 것을 확인할 수 있었다.

다음 연구에서도 이미 보고가 되어 있는 Drosophila melanogaster의 번데기와 성충단계에서의 corazonin 발현 양상과 비교하여 scuttle fly의 번데기와 성충단계에서의 corazonin 발현 패턴을 확인하여야 하겠다.

\section{ACKNOWLEDGEMENT}

None.

\section{CONFLICT OF INTEREST}

The authors affirm that they have no academic, financial or rights interests.

\section{REFERENCES}

Allan DW, Park D, St Pierre SE, Taghert PH, Thor S. Regulators acting in combinatorial codes also act independently in single differentiating neurons. Neuron. 2005. 45: 689-700.

Allan DW, St Pierre SE, Miguel-Aliaga I, Thor S. Specification of neuropeptide cell identity by the integration of retrograde BMP signaling and a combinatorial transcription factor code. Cell. 2003. 113: 73-86.

Altstein M, Nassel DR. Neuropeptide signaling in insects (Geary TG, Maule AG. Eds). Neuropeptide Systems as Targets for Parasite and Pest Control. 2010. pp. 155-165.

Awad TA, Truman JW. Postembryonic development of the midline glia in the CNS of Drosophila: proliferation, programmed cell death, and endocrine regulation. Dev Biol. 1997. 187: 283 $-297$.

Baraban SC, Tallent MK. Interneuron Diversity series: Interneuronal neuropeptides - endogenous regulators of neuronal excitability Trends Neurosci. 2004. 27: 135-142.

Benveniste RJ, Thor S, Thomas JB, Taghert PH. Cell type-specific regulation of the Drosophila FMRF-NH2 neuropeptide gene by Apterous, a LIM homeodomain transcription factor. Devel- 
opment. 1998. 125: 4757-4765.

Brodsky MH, Nordstrom W, Tsang G, Kwan E, Rubin GM, Abrams JM. Drosophila p53 binds a damage response element at the reaper locus. Cell. 2000. 101: 103-113.

Cantera R, Veenstra JA, Nassel DR. Post-embryonic development of Corazonin-containing neurons and neruosecretory cells in the Blowfly, Phormia terraenovae. J Comp Neurol. 1994. 350: 559-572.

Cazzamali G, Saxild N, Grimmelikhuijzen C. Molecular cloning and functional expression of a Drosophila corazonin receptor. Biochem Biophys Res Commun. 2002. 298: 31-36.

Choi SH. "The Regulation of Neuropeptide Corazonin and Its Functional Analyses in Drosophila melanogaster." PhD diss., University of Tennessee. 2009.

Choi SH, Lee G, Monahan P, Park JH. Spatial regulation of Corazonin neuropeptide expression requires multiple cis-acting elements in Drosophila melanogaster. J Comp Neurol. 2008. 507: 1184-1195.

Choi YJ, Lee G, Park JH. Programmed cell death mechanisms of identifiable peptidergic neurons in Drosophila melanogaster. Development. 2006. 133: 2223-2232.

Choi YJ, Lee G, Hall JC, Park JH. Comparative analysis of Corazonin-encoding genes (Crz's) in Drosophila species and functional insights into Crz-expressing neurons. J Comp Neurol. 2005. 482: 372-385.

Draizen TA, Ewer J, Robinow S. Genetic and hormonal regulation of the death of peptidergic neurons in the Drosophila central nervous system. J Neurobiol. 1999. 38: 455-465.

Gauthier SA, Hewes RS. Transcriptional regulation of neuropeptide and peptide hormone expression by the Drosophila dimmed and cryptocephal genes. J Exp Biol. 2006. 209: 1803-1815.

Gruntenko N, Chentsova NA, Bogomolova EV, Karpova EK, Glazko GV. The effect of mutations altering biogenic amine metabolism in Drosophila on viability and the response to environmental stresses. Arch Insect Biochem Pysiol. 2004. 55: 55-67.

Hansen IA, Sehnal F, Meyer SR, Scheller K. Corazonin gene expression in the waxmoth Galleria mellonella. Insect Mol Biol. 2001. 10: 341-346.

Hauser F, Cazzamali G, Williamson M, Blenau W, Grimmelikhuijzen CJ. A review of neurohormone GPCRs present in the fruitfly Drosophila melanogaster and the honey bee Apis mellifera. Prog Neurobiol. 2006. 80: 1-19.

Hökfelt T. Neuropeptides in perspective: the last ten years. Neuron. 1991. 7: 867-879.
Horodyski FM, Ewer J, Riddiford LM, Truman JW. Isolation, characterization and expression of the eclosion hormone gene of Drosophila melanogaster. Eur J Biochem. 1993. 215: 221 -228 .

Hummon AB, Richmond TA, Verleyen P, Baggerman G, Huybrechts J, Ewing MA, Vierstraete E, Rodriguez-Zas SL, Schoofs L, Robinson GE. From the genome to the proteome: uncovering peptides in the Apis brain. Science. 2006. 314 647-649.

Isabel G, Martin JR, Chidami S, Veenstra JA, Rosay P. AKHproducing neuroendocrine cell ablation decreases trehalose and induces behavioral changes in Drosophila. Am J Physiol Regul Integr Comp Physiol. 2005. 288: R531-R538.

Karcavich R, Doe CQ. Drosophila neuroblast 7-3 cell lineage: a model system for studying programmed cell death, Notch/ Numb signaling, and sequential specification of ganglion mother cell identity. J Comp Neurol. 2005. 481: 240-251.

Kim J, Kim JW, Park JH. Characterization and expression of corazonin gene in the scuttle fly, Megaselia scalaris. GenBank. 2013. KF318884.1.

Kimura KI, Truman JW. Postmetamorphic cell death in the nervous and muscular systems of Drosophila melanogaster. J Neurosci. 1990. 10: 403-411.

Lee G, Kim KM, Kikuno K, Wang Z, Choi YJ, Park JH. Developmental regulation and functions of the expression of the neuropeptide corazonin in Drosophila melanogaster. Cell Tissue Res. 2008. 331: 659-673.

Lee G, Park JH. Hemolymph sugar homeostasis and starvationinduced hyperactivity affected by genetic manipulations of the adipokinetic hormone-encoding gene in Drosophila melanogaster. Genetics. 2005. 167: 311-323.

Lee G, Wang Z, Sehgal R, Chen CH, Kikuno K, Hay B, Park JH. Drosophila caspases involved in developmentally regulated programmed cell death of peptidergic neurons during early metamorphosis. J Comp Neurol. 2011. 519: 34-48.

Lundell MJ, Lee HK, Pe'rez E, Chadwell L. The regulation of apoptosis by Numb/Notch signaling in the serotonin lineage of Drosophila. Development. 2003. 130: 4109-4121.

McNabb SL, Baker JD, Agapite J, Steller H, Riddiford LM, Truman JW. Disruption of a behavioral sequence by targeted death of peptidergic neurons in Drosophila. Neuron. 1997. 19: 813-823.

Menzies FM, Tenisetti SC, Min KT. Roles of Drosophila DJ-1 in survival of dopaminergic neurons and oxidative stress. Curr Biol. 2005. 15: 1578-1582.

Nässel DR. Neuropeptides in the nervous system of Drosophila 
and other insects: multiple roles as neuromodulators and neurohormones. Prog Neurobiol. 2002. 68: 1-84.

Nässel DR, Winther AM. Drosophila neuropeptides in regulation of physiology and behavior. Prog Neurobiol. 2010. 92: 42-104.

Neckameyer WS, Weinstein JS. Stress affects dopaminergic signaling pathways in Drosophila melanogaster. Stress. 2005. 9: 117-131.

Novotny T, Eiselt R, Urban J. Hunchback is required for the specification of the early sublineage of neuroblast 7-3 in the Drosophila central nervous system. Development. 2002. 129: 1027-1036.

O'Shea M, Schaffer M. Neuropeptide function: the invertebrate contribution. Annu Rev Neurosci. 1985. 8: 171-198.

Park HH. The development stages of scuttle fly. Biomedical Science Letters. 2018. 24: 125-129.

Park HH, Park MS, Na KJ. Development of Central Nervous System in Scuttle Fly. Korean Clin Lab Sci. 2018. 50: 284 $-288$.

Park Y, Kim YJ, Adams ME. Identification of G protein-coupled receptors for Drosophila PRXamide, CCAP, corazonin, and AKH supports a theory of ligand-receptor coevolution. Proc Natl Acad Sci USA. 2002. 99: 11423-11428.

Porras MG, De Loof A, Breuer M, Arechiga H. Corazonin promotes tegumentary pigment migration in the crayfish Procambarus clarkii. Peptides. 2003. 24: 1581-1589.

Rauschenbach IY, Serova L, Timochina I, Chentsova NA, Schumnaja L. Analysis of differences in dopamine content between two lines of Drosophila virilis in response to heat stress. J Insect Physiol. 1993. 39: 761-767.

Robinow S, Talbot WS, Hogness DS, Truman JW. Programmed cell death in the Drosophila CNS is ecdysone-regulated and coupled with a specific ecdysone receptor isoform. Development. 1993. 119: 1251-1259.

Roller L, Tanaka S, Kimura K, Satake H, Tanaka Y. Molecular cloning of $\left[\mathrm{Thr}^{4}, \mathrm{His}^{7}\right]$-corazonin(Apime-corazonin) and its distribution in the central nervous system of the honey bee Apis melifera (Hymenoptera; Apidae). Appl Entomol Zool. 2006. 41: 331-338.

Roller L, Tanaka Y, Tanaka S. Corazonin and corazonin-like substances in the central nervous system of the Pterygote and Apterygote insects. Cell Tissue Tes. 2003. 312: 393-406.

Santos JG, Vömel M, Struck R, Homberg U, Nässel DR, Wegener C. Neuroarchitecture of peptidergic systems in the larval ventral ganglion of Drosophila melanogaster. PLoS ONE. 2007. 2: e695.
Sha K, Conner WC, Choi DY, Park JH. Characterization, expression, and evolutionary aspects of Corazonin neuropeptide and its receptor from the House Fly, Musca domestica (Diptera: Muscidae). Gene. 2012. 497: 191-199.

Shiga S, Davis NT, Hildebrand JG. Role of neurosecretory cells in the photoperiodic induction of pupal diapause of the tobacco hornworm Manduca sexta. J Comp Neurol. 2003. 462: 275 -285 .

Taghert PH, Veenstra JA. Drosophila neuropeptide signaling. Adv Genet. 2003. 49: 1-65.

Tanaka S. Endocrine mechanism of controlling body-color polymorphism in locusts. Arch Insect Biochem Physiol. 2001. 47: 139-149.

Tanaka S, Zhu DH, Hoste B, Breuer M. The dark-color inducing neuropoptide, His7-corazonin, causes a shift in morphometric characteristics towards the gregarious phase in isolated-reared (solitarious) Locusta migratoria. J. Insect Physiol. 2002a. 48: 1065-1074.

Tan Y, Yamada-Mabuchi M, Arya R, St Pierre S, Tang W, Tosa M, Brachmann C, White K. Coordinated expression of cell death genes regulates neuroblast apoptosis. Development. 2011. 138: 2197-2206

Tawfik AI, Tanaka S, De Loof A, Schoofs L, Baggerman G, Waelkens E, Derua R, Milner Y, Yerushalmi Y, Pener MP. Identification of the gregarization - associated dark - pigmentotropin in locusts through an albino mutant. Proc Natl Acad Sci U S A. 1999. 96: 7083-7087.

Tayler TD, Pacheco DA, Hergarden AC, Murthy M, Anderson DJ. A neuropeptide circuit that coordinates sperm transfer and copulation duration in Drosophila. Proc Natl Acad Sci U S A. 2012. 109: 20697-20702.

Terhzaz S, Rosay P, Goodwin SF, Veenstra JA. The neuropeptide SIFamide modulates sexual behavior in Drosophila. Biochem Biophys Res Commun. 2007. 352: 305-310.

Truman JW. Metamorphosis of the central nervous system of Drosophila. J Neurobiol. 1990. 21: 1072-1084.

Veenstra JA. Isolation and structure of corazonin, a cardio-active peptide from the America cockroach. FEBS Lett. 1989. 250: 231-234.

Veenstra JA. Presence of corazonin in three insect species, and isolation and identification of [His7] corazonin from Schistocerca americana. Peptides. 1991. 12: 1285-1289.

Veenstra JA. Does Corazonin signal nutritional stress in insects? Insect Biochem Mol Biol. 2009. 39: 755-762.

Veenstra JA, Davis NT. Localization of corazonin in the nervous 
system of the cockroach Periplaneta americana. Cell Tissue Res. 1993. 274: 57-64.

Verleyen P, Baggerman G, Mertens I, Vandersmissen T, Huybrechts J, Van Lommel A, De Loof A, Schoofs L. Cloning and characterization of a third isoform of corazonin in the honey bee Apis mellifera. Peptides. 2006. 27: 493-499.

Verleyen P, Huybrechts J, Baggerman G, Van Lommel A, De Loof

A, Schoofs L. SIFamide is a highly conserved neuropeptide: a comparative study in different insect species. Biochem Biophys Res Commun. 2004. 320: 334-341.

Winbush A, Weeks JC. Steroid-triggered, cell-autonomous death of a Drosophila motoneuron during metamorphosis. Neural Dev. 2011. 6: 15.
Yerushalmi YK, Bhargava C, Gilon, Pener MP. Structure-activity relations of the dark-colour-inducing neurohormone of locusts. Insect Biochem Mol Biol. 2002. 32: 909-917.

Zhao Y, Bretz CA, Hawksworth SA, Hirsh J, Johnson EC. Corazonin neurons function in sexually dimorphic circuitry that shape behavioral responses to stress in Drosophila. PLoS One. 2010. 5: e9141.

https://doi.org/10.15616/BSL.2020.26.3.217

Cite this article as: Park $\mathrm{H}$. The Expression of Corazonin Neurons in Larvae Stage of Scuttle Fly. Biomedical Science Letters. 2020. 26: 217-225. 